\title{
A crise que não se parece com nenhuma outra: reflexões sobre a "corona-crise"
}

\author{
José Álvaro de Lima Cardoso ${ }^{1}$ \\ https://orcid.org/0000-0001-5962-2056 \\ ${ }^{1}$ Departamento Intersindical de Estatísticas e Estudos Sócio Econômicos, Escritório Regional de Santa Catarina, Florianópolis, SC, \\ Brasil
}

\section{A crise que não se parece com nenhuma outra: reflexões sobre a "corona-crise"}

Resumo: O objetivo deste artigo é aprofundar o debate sobre a crise econômica mundial, que já vinha se configurando, mas que foi imensamente catalisada pela crise do Covid-19. A análise, amparada em dados de instituições especializadas, procura, a partir dos indicadores da crise global, fazer sempre o contraponto com o Brasil. Uma das conclusões em destaque no texto é a de que a crise atual, também chamada de "corona-crise", é uma das mais relevantes da história, e já supera a Grande Depressão de 1929, especialmente na velocidade com que a economia mundial se deteriora. Nesta crise, a piora dos indicadores macros econômicos e sociais, que nos anos de 1930, se desenvolveram em três anos, ocorreu em três semanas. O artigo também constata que o Brasil enfrenta um somatório de crises simultâneas, que se influenciam mutuamente.

Palavras-chave: Crise. Econômica. Internacional. Desemprego. Depressão.

Recebido em 08.05.2020. Aprovado em 15.06.2020. Revisado em 02.07.2020.

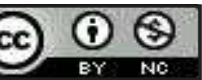

C O(s) Autor(es). 2020 Acesso Aberto Esta obra está licenciada sob os termos da Licença Creative Commons Atribuição-NãoComercial 4.0 Internacional (https://creativecommons.org/licenses/by-nc/4.0/deed.pt_BR), que permite copiar, distribuir e reproduzir em qualquer meio, bem como adaptar, transformar e criar a partir deste material, desde que para fins não comerciais e que você forneça o devido crédito aos autores e a fonte, insira um link para a Licença Creative Commons e indique se mudanças foram feitas. 


\section{Introdução}

Este artigo traz inicialmente uma análise do desenvolvimento das crises (econômica e sanitária) nos diversos países do mundo, objetivando entender a gravidade do problema e a forma como os vários governos o estão enfrentando. $\mathrm{O}$ mundo atravessa hoje o que alguns economistas denominaram de "corona-crise". A brutal crise econômica em curso, comparável à Grande Depressão de 1929, não foi causada, e sim acelerada pela pandemia do Covid-19. Esta já é a maior crise econômica e financeira global desde os anos de 1930, e foi denominada pelo Fundo Monetário Internacional (FMI) de "great lockdown". Se esta crise ainda não superou a de 1929 (é difícil ser categórico, em face da escassez de indicadores comparáveis entre uma crise e outra), a julgar pela velocidade dos acontecimentos, irá superá-la.

Do ponto de vista médico essa crise é muito grave. Um grupo de pesquisadores da Escola de Saúde Pública da Universidade Harvard ${ }^{1}$, chegou à conclusão de que os esforços de distanciamento social para evitar o colapso hospitalar diante da pandemia de covid-19 podem ser necessários, ao menos de modo intermitente, até 2022. No mundo todo, a pandemia está longe de ser "democrática", como desejariam alguns. É óbvio que quem morre são os mais pobres. As classes médias estão sendo atingidas, mas os grupos vulneráveis economicamente são os mais impactados e respondem pelo grosso das mortes. Estima-se que um quarto da população mundial vive em favelas. No Brasil são 13,6 milhões nessa condição. Isso significa que, muitas vezes, oito ou nove pessoas, se amontoam em um, ou dois cômodos. Nessa condição é impossível evitar a aglomeração de pessoas, sair para a rua acaba sendo inevitável.

A partir desse olhar sobre o que acontece no mundo, procuramos analisar um pouco o quadro no Brasil, que atravessa uma crise política e econômica dramáticas. A crise brasileira atual é muito grave, porque sintetiza:

a) crise econômica mundial inusitada;

b) crise dramática da economia brasileira: país vem de três anos de estagnação, após dois anos de brutal recessão (2015/2016). Recessão muito piorada pelo golpe de Estado de 2016;

c) uma pandemia que já é a mais grave do último século;

d) crise política aguda, com grande polarização na sociedade.

Essa conjunção de crises acontece no momento em que o Brasil tem o pior governo da história: o mais entreguista e o mais servil a interesses geopolíticos gigantescos. Um governo que pretende inviabilizar o país enquanto nação e que planeja destruir completamente a soberania brasileira, entregar a Amazônia, a nossa fronteira marítima. Que está destruindo a ciência nacional, sucateia as universidades federais e os Institutos Federais, cortou o orçamento científico em mais de 60\%. A lista de atrocidades cometidas a partir do golpe de 2016, que foi muito aumentada neste governo, é muito longa.

Em decorrência dessa combinação macabra, o Brasil é o caso mais problemático do mundo, no que se refere ao enfrentamento da pandemia e está se tornando o epicentro mundial da doença, rapidamente. É que o controle da pandemia pressupõe foco, estratégia e planejamento, além de compromisso com o bem-estar da população, elementos absolutamente estranhos a esse governo, em todas as áreas.

Neste texto, inicialmente abordamos a crise econômica no mundo, procurando analisar como os diversos países têm procurado enfrentá-las, verificando as diferenças e semelhanças na abordagem do problema. Num segundo momento analisamos brevemente a situação da economia estadunidense, em função do peso que tem na economia mundial e do fato de que, na condição de cabeça dos países imperialistas, suas ações têm sempre grande repercussão mundial.

Posteriormente, trazemos alguns elementos que ilustram a gravidade da crise no mundo e as opções de enfrentamento adotadas nos diferentes países. Em seguida, analisamos o caso brasileiro, que, no momento, enfrenta o que se pode denominar de "tempestade perfeita". Finalmente, como notas conclusivas, procuramos refletir sobre algumas tendências gerais no mundo, nos aspectos econômicos e políticos.

\section{Crise econômica espalhada no mundo}

A previsão do $\mathrm{FMI}^{2}$ é que o Produto Interno Bruto (PIB) da economia global cairá 3\% em 2020. Para efeitos comparativos, a recessão da crise financeira global de 2008 registrou um recuo do PIB de $-0,1 \%$ em 2009. Com esses números de queda do produto global pode-se imaginar o que isso significará em termos de elevação da pobreza e da fome no mundo.

Na previsão do FMI o comércio internacional apresentará queda de volume em $-11 \%$ em 2020 . O relatório estima ainda que dos 189 países no mundo 170 terão queda na variação do PIB, o que revela a abrangência da crise atual. Os preços das commodities caíram dramaticamente em função da retração da demanda. O retrocesso maior está sendo por conta do petróleo, que teve queda sem precedentes do consumo: 
o barril WTI, referência para o mercado americano, tem apresentado cotação negativa. Os especialistas estimam que o preço do petróleo caia mais de $40 \%$ em 2020, devido à baixa demanda global.

Obviamente todas estas projeções devem ser olhadas com cautela, na medida em que o desempenho da economia global irá depender da interação de fatores de difícil previsão, como a evolução da pandemia, da intensidade e duração das medidas de isolamento, dimensão do choque de oferta devido à interrupção de cadeias produtivas, da repercussão do choque financeiro etc. Isso significa que o desempenho da economia global poderá ser ainda pior do que o que tem sido projetado pelas instituições mundiais, como FMI e Banco Mundial.

A previsão do FMI é que o grupo das economias avançadas será o principal responsável pela contração da economia global neste ano. Possivelmente em função de que a crise sanitária teve seu epicentro sucessivo nas economias mais ricas do planeta, atingindo primeiramente a China, posteriormente a Europa e, em abril os Estados Unidos ${ }^{3}$. Esse conjunto de países ricos deverá ter queda do PIB de 6,1\%, ou seja, deverá cair em percentual dobrado em relação à média mundial. O maior declínio do PIB deverá ser registrado na Área do Euro (-7,5\%), devido à gravidade da epidemia na Itália e na Espanha e, em menor medida, na França e na Alemanha. Recuos intensos nos desempenhos econômicos também são esperados para o Reino Unido ($6,5 \%)$, Estados Unidos (-5,9\%) e Japão (-5,2\%), países que compõem o centro imperialista mundial. Numa situação não tão adversa estão os países que tiveram maior êxito na contenção do covid-19, como China, Singapura, Hong Kong, Coreia do Sul, Vietnã.

Nos países subdesenvolvidos as crises são várias e adquirem contornos específicos:

a) um choque sanitário, em face a sistemas precários, ou inexistentes, de saúde pública;

b) choque econômico brutal, com colapso da demanda externa e interna;

c) queda dos preços das commodities;

d) fortes depreciações cambiais.

Os fatores acima, graves por si só, potencializam-se mutuamente. A previsão do FMI é de uma queda de $1 \%$ na variação média do PIB no grupo das economias subdesenvolvidas (que o Fundo chama de países emergentes e em desenvolvimento). Esse resultado esconde, contudo, forte heterogeneidade. A chamada Ásia emergente deve apenas se desacelerar, mantendo-se com desempenho positivo $(+1 \%$ no ano), em função principalmente de China $(+1,2 \%)$ e Índia $(+1,9 \%)$. Mas outras regiões, como a América Latina e a Europa emergente, terão queda acentuada do seu PIB, possivelmente acima de 5\%. Para o Brasil, a previsão do FMI e do Banco Mundial é de uma queda de 5\%, pelo menos. Será um desempenho abaixo do da América Latina, para o qual os organismos de análise econômica estão prevendo contração de 4,6\% (Banco Mundial).

A gravidade da crise pode ser mais bem avaliada a partir dos indicadores da Alemanha, maior economia da Europa. A economia desse país já vinha numa espécie de "limbo". Em 2019, por exemplo, teve o pior crescimento dos últimos seis anos $(0,6 \%)$. Mas a pandemia causada pelo Novo coronavírus colocou essa economia numa situação ainda mais precária, levando, possivelmente à mais grave recessão do pós-segunda guerra. O desemprego, de 5,8\%, aumentou 13,2\% em abril, a maior alta de um mês desde 1991. É a primeira vez no pós-guerra que a taxa de desemprego cresce durante o mês de abril, que marca o início da primavera no Hemisfério Norte, período do qual há um esperado aquecimento do mercado de trabalho.

A queda do PIB alemão, pela previsão do governo, deverá chegar a 6,3\% neste ano, a maior desde que estes cálculos começaram a ser divulgados, em 1970. Outro indicador da gravidade da situação alemã são os números da produção industrial, que já vêm em queda desde 2019, mas é um problema que agora se acentuou. No mês de março a Alemanha sofreu redução histórica de $9,2 \%$ na produção industrial, na comparação com fevereiro. Segundo a Destatis, agência de estatísticas do país, foi a maior queda verificada desde o início da construção da base de dados, em janeiro de 1991. A queda só não foi maior porque o setor de construção civil apresentou aumento da produção de $1,8 \%$ no mês. Comparados com março de 2019 , a produção industrial alemã apresentou queda de $11,6 \%$.

A crise da maior economia da Europa teve um efeito imediato sobre toda a zona do Euro. Para 2020, prevê-se que a contração do PIB chegue a 7,5\% para o conjunto dos 19 países da zona do Euro. Nesse quadro, o desemprego na Eurozona começou a disparar, 7,4\% (quase 12 milhões de desempregados) em março. Os países campeões do desemprego na Europa são a Grécia com o maior índice 16,4\% (dados de janeiro), seguida pela Espanha, com 14,5\% também no mês de março. Além da elevação brutal do desemprego, a deterioração do mercado de trabalho é acrescida do aumento da informalidade em toda a região.

A previsão é que somente os países emergentes da Ásia terão um crescimento positivo de $+1 \%$, incluindo a China, que pode esperar um aumento de $1,2 \%$ em seu PIB, e Índia, cujo crescimento previsto é 1,9\%. O FMI prevê uma queda de 1,6\% no PIB da África Subsaariana (região ao sul do Saara), que deve experimentar um decrescimento de $1,6 \%$, com risco de uma crise alimentar. Tudo indica que haverá na região um brutal aumento da fome. No mundo todo a crise evidenciou um conjunto de desigualdades, agora aumentadas: renda, 
educação, acesso à equipamento digital, acesso à Internet, outras. Além das desigualdades ligadas ao patrimônio, como acesso à habitação, fundamental em tempos de isolamento social.

Pelo que se observa em termos de desenvolvimento da crise, a tendência é a pandemia piorar muito a situação da classe trabalhadora e acirrar a luta de classes. Assim, é ilusão achar que as contradições de classe, e entre países imperialistas e subdesenvolvidos, irão amainar por causa da pandemia. A pobreza e a insegurança no emprego se intensificaram ainda mais com o resultado da crise. Em cada país capitalista a burguesia procura manobrar a crise e seus desdobramentos, a partir de seus interesses de classe. As saídas nunca são neutras, mas moldadas a partir dos interesses de quem detém o poder.

O processo de crise econômica está sendo muito mais profundo e acelerado do que o observado na crise de 2008 e na Grande Depressão de 1929. O economista Noriel Roubini - cujas análises que antes eram consideradas pessimistas, são agora vistas como realistas - registra que naquelas duas grandes crises as bolsas de valores caíram em 50\% ou mais, os mercados de crédito congelaram, as grandes falências aconteceram, as taxas de desemprego subiram acima de $10 \%$ e o PIB encolheu a uma taxa anualizada de $10 \%$ ou mais. Mas todos esses fenômenos aconteceram em três anos, ou mais. Na atual crise, registra Roubini, tudo isso se materializou em três semanas. Em três semanas, um mês, os elementos que compõem a chamada demanda agregada (consumo, gasto de capital, exportações) se encontram em queda livre, como nunca observado antes. É como se tivéssemos a reincidência de uma grave doença, cujos impactos sobre o organismo acontecem, na reincidência, de forma muito mais veloz. A informação é duplamente negativa: volta da doença e a velocidade com que ela se espalha. Obviamente parte dessa velocidade de propagação da crise está relacionada com a globalização da economia, e da informação, especialmente em relação à 1929. Mas em 2007 a economia era tão globalizada quanto hoje. A velocidade com que a informação circula nos mercados hoje é parecida com a existente em 2007/2008.

A gravidade da crise pode ser medida também com base no que está acontecendo com a economia chinesa, motor da economia mundial nos últimos anos: contração de 6,8\% do PIB no primeiro trimestre de 2020, em comparação com o mesmo período no ano anterior. Pior queda em um único trimestre que a China registrou desde que começou a publicar esses números, em 1992. A previsão de crescimento (1,2\% para o ano, como vimos), representa o pior desempenho anual do PIB do país desde a recessão de 1976, quando a morte do líder do Partido Comunista Mao Tsé-Tung encerrou um tumulto social e econômico de uma década (há 44 anos atrás). $\mathrm{O}$ raciocínio é elementar: se a China, economia mais dinâmica do mundo, um país que deu uma verdadeira aula de como se enfrenta uma peste, teve o pior trimestre da história, e que tem projeto nacional de desenvolvimento, o que pode acontecer com o Brasil, que é o pior caso de enfrentamento da doença do mundo?

\section{Crise na economia norte-americana}

A intensidade dos problemas econômicos nos Estados Unidos, epicentro do capitalismo global, é um termômetro da gravidade da crise atual. O FMI calcula que a economia norte-americana irá apresentar retração em 5,9\% no seu Produto Interno Bruto (PIB), fato inédito. Este resultado interrompe 10 anos de crescimento, ciclo iniciado em 2010, a partir da grande recessão mundial ocorrida no período 2007-2009. Período de crescimento, aliás, considerado incomum não só pela sua duração, como também pela taxa razoável de crescimento ( $2 \%$ ao ano, em média).

A queda abrupta e profunda do PIB levou a um crescimento dramático do desemprego na maior economia do planeta. O país registrou em abril um índice de desemprego de 14,7\%, o mais elevado em mais de 70 anos e a maior taxa de desemprego desde que os registros começaram a ser realizados em 1948. Ainda em fevereiro deste ano, o desemprego chegava ao menor percentual da história, de 3,5\%, o que mostra o agravamento do problema em tempo tão curto, resultado da pandemia. Segundo o Departamento de Emprego dos Estados Unidos, até 20,5 milhões de pessoas perderam o emprego em abril último.

Segundo informações oficiais, a crise atual destruiu, no primeiro mês, todos os empregos gerados após a grande crise econômica de 2007/2009. Para efeito de comparação, durante aquela crise, os Estados Unidos, teriam alcançado um pico de desemprego na casa de $10 \%$, em outubro de 2009 . No período todo da crise teriam sidos destruídos mais de 8 milhões de postos de trabalho, contra mais de 20 milhões em um mês, nesta crise. A brutal taxa de desemprego nos Estados Unidos é agravada pela imensa desigualdade, que aflora no indicador de desemprego: para o índice geral, que por si só é explosivo, ele ainda varia bastante entre as etnias. Entre os brancos o desemprego foi de 14,2\% em abril, para os afro-americanos foi de 16,7\% e, entre os hispânicos chegou a $18,9 \%$.

Mesmo usufruindo de todas as vantagens de ser o principal país imperialista da terra, os EUA enfrentam grandes contradições internas, porque o seu modelo de desenvolvimento gera grande desigualdade social. Pelo 
menos desde o governo de Ronald Reagan (1981/1989), o estado de bem-estar norte-americano, que já era fraco, foi sendo paulatinamente destruído. Se estima que atualmente existam mais de 40 milhões de pobres nos EUA. Cerca de $40 \%$ dos estadunidenses se queixam de que não conseguem cobrir despesas inesperadas com emergências, que ultrapassem 400 dólares ${ }^{4}$. O fato de que os EUA tenham um número tão grande na condição de pobreza, representa uma verdadeira bomba relógio. Uma sublevação dos trabalhadores dentro do país imperialista mais rico do mundo teria um efeito político, econômico e social, simplesmente imprevisível. Risco que deve ter influenciado a decisão dos EUA, há cerca de uma década, de "retomar" os governos da América Latina para sua área de influência.

\section{A gravidade da crise e as ações de enfrentamento em todo o mundo}

No sistema capitalista o mercado de trabalho funciona como uma "variável de ajuste" do empresariado. $\mathrm{Na}$ hora $\mathrm{H}$, quando a crise aperta, o empresariado demite os trabalhadores, sem mais delongas. Daí a luta entre as classes em torno da legislação trabalhista. Os empresários odeiam regulamentação do mercado de trabalho porque, quando surge a crise, aquela significa um obstáculo no ajuste de custos. A existência do posto de trabalho, no sistema capitalista, só se justifica, se o capitalista puder se apropriar de uma parte do valor produzido pelo trabalhador. Caso não seja esta a lógica, o sistema não seria capitalista. No caso do Brasil, país subdesenvolvido e dependente, nunca houve uma cultura de preservação dos empregos (rara, aliás, mesmo nos países capitalistas centrais), que garantisse minimamente o bem-estar das pessoas e o mercado consumidor interno.

$\mathrm{Na}$ hora do agravamento da crise econômica os empresários têm uma hierarquia de estratégias para enfrentar o problema, na qual o sacrifício do emprego é a primeira a ser utilizada. A taxa de rotatividade no Brasil, inclusive, sempre nas alturas, revela como as demissões sempre foram a estratégia preferida dos patrões na hora do aperto trazido pela crise. Se a taxa de rotatividade é monstruosa, a ponto de em algumas categorias rodar $100 \%$ dos trabalhadores em um único ano, é porque não é oneroso demitir, como sempre os patrões alegaram no Brasil.

A pandemia não causou a crise econômica, apenas a acelerou. Algumas análises dão a impressão de que a economia vinha em céu de brigadeiro, de vento em popa, quando veio a pandemia e causou a crise. $\mathrm{O}$ fato é que o tsunami já vinha se armando há um bom tempo. A epidemia apenas antecipou o agravamento da crise. As contradições que levaram à crise de 2007/2008 (causadas pela financeirização da economia) se mantém, não foram resolvidas. Pelo contrário, algumas foram agravadas. Seria de se esperar que uma nova crise adviria mais cedo ou mais tarde. O impacto das duas crises reunidas, sobre a economia e a política no mundo está sendo e será ainda mais dramático. Como o Covid-19 é uma doença desconhecida, para a qual ainda não existe vacina (demorará ainda alguns meses, talvez anos), não se pode estimar ainda a profundidade e a extensão da crise.

Sobre a situação pós-pandemia há um leque de possibilidades. Temos visto algumas análises extremamente otimistas, sobre o pós-Covid-19: de que o mundo será mais harmônico, de que o medo da doença vai aproximar as pessoas, de que o mundo ficará mais solidário. É uma abordagem muito otimista, no mínimo. Não será uma doença que irá acabar com o conflito capital versus trabalho no mundo. Dependendo do que acontecer, a coisa pode piorar. Por exemplo, o governo brasileiro está aproveitando a pandemia para transferir o ônus da crise para o trabalhador, através de inúmeras medidas como as MP 937 e MP 905. Nesse quadro, quando acabar a pandemia o trabalhador estará mais pobre, o padrão de renda e emprego, que já vinha em processo de deterioração, estará em outro patamar.

Se as políticas neoliberais foram fundamentais para transferir, pelo menos em parte, a crise do centro do sistema para a periferia capitalista, ao mesmo tempo elas destruíram as já precárias políticas públicas de atendimento à população, a começar pelos sistemas públicos de saúde e educação. Os Estados Unidos enfrentam uma situação caótica, tornando-se rapidamente o epicentro da pandemia no mundo, com mais de 105 mil mortes e 1,8 milhão de pessoas infectadas pelo Covid-19, até 30 de maio de 2020. De outro lado, o Estado chinês colocou seus recursos e sua força organizadora na resposta à pandemia. A estruturação do atendimento aos pacientes realizada de forma extremamente ágil, a organização da população, a adaptação da produção industrial às necessidades de combate à doença, a construção de hospitais em tempo recorde, a disponibilização de um grande número de testes “ ações basicamente levadas à cabo pelo Estado encaminharam para um rápido controle da doença. Por mais influenciável que seja pela mídia hegemônica, uma parte das pessoas percebe essas diferenças ${ }^{5}$.

Para sentirmos o drama da crise, é didático prestar atenção no que os países ricos vêm fazendo para enfrentá-la. As medidas que esses países, que normalmente têm informações privilegiadas, estão tomando, nos devem servir de alerta acerca da gravidade da crise. A Alemanha, por exemplo, a "pátria da austeridade 
fiscal" (4 PIB do mundo), está colocando 35\% do seu PIB no combate às crises. Os Estados Unidos aprovaram o mais importante plano econômico da história da economia mundial. A previsão é de um gasto inicial de quase dois trilhões de dólares, equivalente a cerca de R $\$ 10$ trilhões (para efeito de comparação, o PIB brasileiro no ano passado foi de R \$ 7,3 trilhões). Irão colocar no final da pandemia, mais dois trilhões de dólares. Essa fábula de dinheiro, um antídoto contra a crise econômica e a pandemia, prevê injeções maciças nas empresas e até nos bolsos dos cidadãos.

O grosso desses investimentos nos países ricos, está sendo feito nas empresas. Os Estados são comandados pelas burguesias de cada país. Lá, como aqui, os governos querem resolver o problema da burguesia. Claro que tem diferenças, no tratamento dos trabalhadores lá e aqui, porque o Brasil é um país subdesenvolvido e dependente. Os Estados Unidos é o país imperialista principal do globo, que drena recursos do mundo todo para garantir os seus interesses. Acabou inclusive de coordenar um golpe no Brasil para tomar o pré-sal e outras riquezas. Assim como em vários países latino-americanos. Portanto tem muito mais recursos, inclusive para colocar dinheiro diretamente no bolso da maioria da população. Os repasses diretos de dinheiro, que alcançaram a maior parte dos cidadãos norte-americanos, são de 1.200 dólares por pessoa adulta e 500 dólares por cada menor de idade. Essa ajuda direta aos cidadãos poderá alcançar 500 bilhões de dólares. O plano prevê também uma linha de crédito de 367 bilhões de dólares para pequenas e médias empresas, e um fundo de 500 bilhões para indústrias, cidades e estados. Os trabalhadores demitidos receberão o seguro-desemprego durante quatro meses, no valor habitualmente pago em seu Estado, mais um dinheiro extra de 600 dólares.

Da mesma forma que nos Estados Unidos, a União

Essa conjunção de crises

acontece no momento em que

o Brasil tem o pior governo

da história: o mais

entreguista e o mais servil a

interesses geopolíticos

gigantescos. Um governo que

pretende inviabilizar o país

enquanto nação e que planeja

destruir completamente a

soberania brasileira, entregar

a Amazônia, a nossa fronteira

marítima.

Europeia (UE) fez um pacote de medidas econômicas de 500 bilhões de euros (2,8 trilhões de reais, $40 \%$ do PIB brasileiro) para apoiar países, empresas e trabalhadores durante a pandemia causada pelo coronavírus. $O$ pacote de medidas adotadas consiste em três pilares: uma linha de crédito do Mecanismo de Estabilidade Europeu, o fundo de resgate da zona do euro, com 240 bilhões de euros em empréstimos; um fundo de garantia do Banco Europeu de Investimento com até 200 bilhões de euros em créditos para empresas; e um fundo temporário com 100 bilhões de euros para ajudar no pagamento de salários de trabalhadores e evitar demissões. (Ou seja, na melhor das hipóteses, $20 \%$ apenas do valor vai para os trabalhadores).

Boa parte das economias já precisavam de políticas fiscais vigorosas, antes mesmo da crise da coronavírus. A Itália, por exemplo, o país mais atingido pelo surto na Europa, já estava quase em recessão antes do coronavírus. É o caso também da Alemanha, considerado o motor da economia europeia, que cresceu meros $0,6 \%$ em 2019, uma notável desaceleração em relação a 2017 (2,5\%) e 2018 (1,5\%). Este plano de ajuda às empresas na Alemanha é mais significativo do que o utilizado na crise financeira de 2008. A crise sanitária apenas piorou muito uma situação que já era ruim.

O risco dessa crise afetar o sistema mundial é muito mais grave em 2020, do que foi em 1979, 1987 ou 2008. O risco é mais alto de contaminação do mercado de derivati vos, o que envolve trilhões de dólares. É uma verdadeira fábula de dinheiro aplicada em papéis sem lastro, investimentos financeiros completamente descolados da esfera real da economia.

A perspectiva de uma grande crise internacional, acelerada por uma brutal pandemia, está levando todos os governos a optarem por ações drásticas, em todo o mundo. Não apenas no campo fiscal, tributário e creditício, mas em áreas diretamente ligadas ao controle da doença. Por exemplo, na Espanha o governo determinou que as autoridades de saúde estatais do país assumam o controle de hospitais privados, para atender e hospitalizar pacientes com coronavírus. Segundo o ministro da saúde da Espanha, a medida visa garantir por todos os meios a saúde e o interesse público e permitir que os cidadãos possam ser atendidos em condições de igualdade. O Ministério da Saúde espanhol determinou também que as empresas e laboratórios particulares que façam diagnósticos ou produzam máscaras e outros utensílios que possam ser usados no combate ao coronavírus, devem informar ao governo da sua existência e da sua capacidade produtiva em até 48 horas. 
A crise é tão grave que foi ativada pela primeira vez uma cláusula de escape geral do Pacto de Estabilidade e Crescimento (PEC). Com a decisão, os 19 países da zona do euro poderão injetar em suas economias "tudo que precisarem de recursos". O PEC, agora suspenso, limita o déficit público a $3 \%$ e a dívida pública a $60 \%$ do PIB, sob pena de sanções econômicas. Com o acionamento da cláusula os países poderão ter déficit elevado e contrair dívida pública acima de $60 \%$ do PIB.

No mesmo dia 20 de fevereiro, o governo britânico anunciou um novo pacote de estímulos para a economia do Reino Unido enfrentar a crise decorrente da doença. Serão mais 38 bilhões de libras (mais de R\$ 223 bilhões). Estes recursos serão usados para garantir o pagamento de $80 \%$ dos salários dos trabalhadores do país pelo período de três meses, a partir de $1^{\circ}$ de março. Com este já são três os pacotes de medidas em menos de duas semanas, totalizando 418 bilhões de libras, ou R \$ 2,5 trilhões. Estamos falando de um montante equivalente a $34 \%$ do PIB brasileiro para medidas de contenção às crises econômica e sanitária. Nunca em toda a história do Estado britânico foi dado um incentivo à economia dessa magnitude, o que nos dá uma ideia do tamanho do tsunami que está se armando no horizonte. As garantias dos salários, inicialmente são para três meses, entre março e maio. Mas, se a crise se aprofundar o prazo pode ser estendido. O governo britânico afirma que não há limites para o valor que pretende gastar.

Na Inglaterra, além do pagamento de $80 \%$ dos salários, (o que significará o gasto de 8 bilhões de libras, quase $\mathrm{R} \$ 47$ bilhões), haverá também a suspensão do IVA (Imposto sobre o Valor Agregado). Esta renúncia ao imposto, para estimular o funcionamento do comércio, representará a perda de receitas na casa dos 30 bilhões de libras (mais de R 176 bilhões). É um valor equivalente a 1,5\% PIB inglês. O pacote inclui ainda uma ajuda para locatários de imóveis, em 30\% do valor do aluguel. Ademais, todos os negócios do ramo da hotelaria e restauração tiveram as taxas governamentais suspensas, para garantia de sua sobrevivência.

A pandemia segundo a OIT, na previsão mais moderada poderá aumentar em 5,3 milhões o número de desempregados no mundo. No pior cenário, é possível que o número de desempregados cresça em 24,7 milhões, num universo, segundo a Organização, de 188 milhões de desempregados em 2019. Conforme previsão da OIT aumentará também o subemprego, com as inevitáveis reduções das jornadas de trabalho e dos salários. A Organização divulgou um cálculo da perda de renda pelos trabalhadores, com a crise, que deve ficar entre US\$ 860 bilhões e US\$ 3,4 trilhões até o fim deste ano.

Em 2009, o declínio da produção e do comércio mundial foi interrompido pelos enormes investimentos em infraestrutura feitos pela China. Em 2020, isso já não ocorre e nem há a tendência de isso acontecer, em razão dos ataques que o país sofre para desempenhar aquele mesmo papel. O regime interestatal relativamente cooperativo de 2008-2009, que viu a criação do G20, deu lugar a uma intensa rivalidade comercial e a um grande aumento do protecionismo, provocado fundamentalmente pelo governo de Donald Trump.

Em 2008, as economias ditas emergentes escapam amplamente da crise financeira de 2008 e se recuperam em 2009. Agora elas foram atingidas de forma imediata. Foi o caso do Brasil. Em 1929, a economia mundial era internacionalizada, mas não globalizada. Demorou mais de um ano para que a crise chegasse à Europa. Em 2020, foram necessárias apenas algumas semanas para que a paralisação da produção na China se transformasse em crise global.

Como destacou recentemente o pensador francês Chesne, em 1929, o capitalismo ainda estava em expansão nos anos 1930 e experimentaria, a partir do início dos anos 1940, um longo ciclo de acumulação (ciclo de Kondratiev), impulsionado, em grande parte, pela tecnologia, mas também pela tarefa de completar a expansão mundial das relações de produção capitalistas. Hoje, o capitalismo mundial está diante de uma parede. Ele está sendo confrontado por suas consequências sociais e econômicas, pelo aquecimento global e pelas tecnologias dominantes em razão da inteligência artificial.

A tecnologia do processo de produção é dominada pela robótica, o que reduz drasticamente a necessidade de mão de obra em muitas indústrias e setores de serviços. Quanto à tecnologia materializada nos produtos, sua capacidade de servir como impulsionador da retomada de acumulação depende da importância dos investimentos que a sua utilização supõe. Isso tanto em relação aos ramos industriais onde nascem como em atividades adjacentes. Também dependem da ampliação da demanda criada pela sua utilização social. No que diz respeito à reorganização, tudo o que se pode dizer com certeza é que a importância da China no mundo, aumentará. O processo de reprodução expandida do capital enfrenta uma parede que está ligada às características da tecnologia apresentadas acima e às consequências negativas, mesmo para a acumulação, das mudanças climáticas.

\section{E o Brasil?}

Quem detém o poder, como sempre aconteceu em todas as grandes crises no Brasil, está aproveitando a crise atual para liquidar de vez com os direitos dos trabalhadores. Por exemplo, no início de abril foi aprovado 
o PL 9236/17, que prevê pagamento de um auxílio emergencial aos mais pobres no valor de R $\$ 600$ mensais (durante três meses para as pessoas de baixa renda afetadas pela crise sanitária). Além do valor negociado ser muito baixo (uma cesta de alimentos, com 13 produtos essenciais para uma pessoa no mês de março/20, custou em média $\mathrm{R}$ \$ 517,00 em Florianópolis), o benefício até hoje não chegou nas mãos de uma boa parte das pessoas que necessitam. Em todas as regiões do Brasil, milhares de trabalhadores denunciam que não conseguem sacar o recurso em função das exigências burocráticas.

O detalhe importante é que, pelas condições de tecnologia existentes hoje, e pela existência do Cadastro Único para Programas Sociais do governo federal, montado pelos governos anteriores ao golpe de 2016, o benefício poderia começar a ser pago no mesmo dia de aprovação do PL no Congresso Nacional. Do ponto de vista prático, dada a importância do benefício, justificaria colocar até as Forças Armadas e Forças Auxiliares, para viabilizar imediatamente a chegada do recurso no bolso de quem já está passando fome. Não fazer isso é, claramente, uma opção do governo, que está preocupado em gastar o menos possível com os pobres, visando sobrar mais recurso para os ricos em geral.

Enquanto a população se concentra no enfrentamento da pandemia, e boa parte dela luta para colocar comida na mesa, aproveitam para fazer os trabalhadores pagarem a conta da crise, sozinhos. Um exemplo de como as elites endinheiradas no Brasil tratam a população. O Ministério Público do Estado Mato Grosso, instituiu no mês de abril um "Bônus covid" de até R \$ 1.000,00 para procuradores, promotores e servidores usarem em gastos de saúde durante a pandemia. A medida, de 04 de maio de 2020 , terá um custo de $\mathrm{R} \$ 680$ mil por mês. Procuradores e promotores têm direito a $\mathrm{R} \$ 1.000,00$ e os demais servidores a $\mathrm{R} \$ 500,00$. O ato administrativo do Ministério Público de Mato Grosso, surge num momento em que a população mofa nas filas da Caixa Econômica Federal tentando sacar os miseráveis R \$ 600,00, para não morrer de fome.

Um segundo exemplo da "consideração" com que tratam o povo no Brasil. No dia 06 a Câmara dos Deputados aprovou em segundo turno a Proposta de Emenda à Constituição (PEC) 10/2020, que permite ao Banco Central (BC) adquirir papéis podres dos grandes bancos e investidores, sem nenhum limite de valor. Especialistas que acompanham de perto o assunto, afirmam que a PEC irá aumentar a dívida pública em vários trilhões de reais. Enquanto o governo propõe destinar R $\$ 200,00$ reais mensais para os desempregados e desamparados (os $\mathrm{R} \$ 600,00$ vieram através de negociação, a partir de uma proposta de $\mathrm{R} \$ 1.000,00$ da oposição) aprovam uma PEC que irá aumentar exponencialmente a dívida pública, a qual, no final das contas, será paga pela população.

O grande empresariado se sente tão à vontade, num país onde metade da população está dependendo dos R \$ 600,00 da Renda Emergencial para não morrer de fome, que às vezes alguns deles tem ataques de "sinceridade inconveniente": Guilherme Benchimol, presidente e fundador da XP Investimentos, afirmou recentemente que o Brasil está indo no caminho certo e já superou o coronavírus nas classes altas e médias. Afirmou em entrevista: "Acompanhando um pouco os nossos números, eu diria que o Brasil está bem. Nossas curvas não estão tão exponenciais ainda, a gente vem conseguindo achatar. Teremos uma fotografia mais clara nas próximas duas a três semanas. O pico da doença já passou quando a gente analisa a classe média, classe média alta".

Por outro lado, há um verdadeiro dilúvio de capitais internacionais que escapam do Brasil. A saída líquida de dólares da economia brasileira no ano passado (entradas menos saídas) foi de US\$ 44,77 bilhões, maior evasão de divisas do Brasil em toda a série histórica, iniciada em 1982. Mas somente neste ano já fugiram praticamente os valores observados em todo o ano passado. Os grandes "investidores" têm grande sede de lucros e pernas longas. Têm também informações privilegiadas, as quais nós, meros vendedores da força de trabalho, não temos acesso. O recorde anterior de fuga de capitais tinha sido registrado em 1999, quando o saldo cambial (diferença entre as entradas e saídas de dólares) fícou negativo em US\$16,18 bilhões. Somente em março, o Banco Central já injetou US\$ 15,245 bilhões em recursos novos no mercado de câmbio, tentando conter a escalada do dólar. Mesmo assim, o real é a moeda que mais se desvalorizou no mundo, neste ano.

\section{Considerações finais}

A partir do diagnóstico colocado, é possível projetar algumas tendências gerais na evolução da economia mundial, conforme segue:

\section{Aumento do endividamento e inadimplência}

Diferentemente de 2007/2009, agora, em 2020, há uma fraqueza das ferramentas monetárias que foram tão importantes em setembro de 2008; a perda de eficácia das intervenções dos bancos centrais e o nível já elevado das dívidas públicas no início da pandemia. A resposta à crise do covid-19 requer um aumento dos 
déficits fiscais dos países em uma ordem de $10 \%$ do PIB ou mais. E isso acontece em um momento em que os níveis da dívida pública em muitos países já eram altos, senão insustentáveis. A perda de renda para muitas famílias e empresas pode gerar uma inadimplência em massa.

No Brasil a situação será pior: recentemente a Câmara dos Deputados aprovou em segundo turno a Proposta de Emenda à Constituição (PEC) 10/2020, que permite ao Banco Central (BC) adquirir papéis podres dos grandes bancos e investidores, sem limite algum. São papéis que estão acumulados há 15 anos, e que significarão um prejuízo do erário público de trilhões de reais! Enquanto a população se distrai, tentado sobreviver ao coronavírus e à fome, aproveitam para depenar o erário público.

\section{Necessidade de maiores investimentos em sistemas de saúde}

A crise do coronavírus mostrou o fracasso dos países que destruíram seus sistemas públicos de saúde, durante décadas de políticas neoliberais. Fica evidente a importância de destinar maiores gastos aos sistemas públicos de saúde. A consequência é que o "financiamento" dessas eventuais despesas com saúde aumentará ainda mais as dívidas implícitas dos atuais sistemas de assistência médica e de seguridade social, já que a população economicamente ativa (e pagadora de impostos) está ficando menor em relação à população que precisa de assistência (os idosos).

\section{Risco de deflação}

A crise do coronavírus também está criando uma "folga" na produção de bens e criando desemprego (além de provocar um colapso dos preços de commodities, como petróleo e metais industriais, cuja demanda diminuiu dramaticamente). Isso torna provável a deflação de preços de uma forma geral. A população não tem renda para consumir os produtos e por isso seus preços caem. Mas o fenômeno gera desemprego em massa e pobreza. A deflação significa que o paciente está debilitado, a economia está perdendo os seus sinais vitais.

\section{Crise no mercado de trabalho}

Milhões de pessoas estão perdendo seus empregos ou tendo sua renda diminuída, as diferenças de "renda" e "riqueza" da economia do século XXI se ampliarão ainda mais. As empresas de economias avançadas repassarão a produção de regiões de baixo custo para mercados domésticos de alto custo, a fim de se proteger de eventuais riscos. Mas nesse caso, essa tendência acelerará o ritmo da automação, pressionando os salários para baixo, aumentando ainda mais a xenofobia.

\section{5. "Desglobalização"}

"A pandemia está acelerando as tendências de desglobalização", segundo o economista Noriel Roubini. Os Estados Unidos e a China se dissociarão mais rapidamente, e a maioria dos países responderá adotando políticas ainda mais protecionistas para proteger empresas e trabalhadores domésticos de rupturas globais.

Como diz Roubini, o mundo pós-pandemia "será marcado por restrições mais rígidas ao movimento de bens, serviços, capital, trabalho, tecnologia, dados e informações”.

\section{As restrições de imigração e comércio tendem a aumentar}

Em condições de maior insegurança econômica, haverá um forte impulso de bode expiatório de estrangeiros e de comércio para a crise.

\section{Aumentam as tensões entre Estado Unidos e China}

Com o governo Trump fazendo todos os esforços para culpar a China pela pandemia, a disputa dos países no comércio, tecnologia, investimento, dados e acordos monetários se intensificará, contaminando o mundo todo. Se dependesse da postura dos Estados Unidos, a disputa viraria guerra rapidamente.

\section{Referências}

GUIMARÃES, Samuel Pinheiro. Estados Unidos \& China: duas estratégias na luta pela hegemonia. Disponível em: https:// outraspalavras.net/geopoliticaeguerra/Estados Unidos-china-duas-estrategias-na-luta-pela-hegemonia/. Acesso em: 10 maio 2020. MOURA, J. Pico de Covid-19 nas classes altas já passou; o desafio é que o Brasil tem muita favela, diz presidente da XP. Disponível em: https://www1.folha.uol.com.br/mercado/2020/05/brasil-esta-indo-bem-no-controle-do-coronavirus-e-pico-nas-classes-altas-japassou-diz-presidente-da-xp.shtml. Acesso em: 07 maio 2020.

MINEIRO, Adhemar. A crise internacional do coronavírus: uma conjuntura difícil no curto-prazo, e de mudanças importantes no médio e no longo prazo. 2020. Disponível em https://www.uscs.edu.br/boletim/5732.pdf. Acesso em: 10 maio 2020. 
RUSSO JÚNIOR, Carlos. 40 milhões de miseráveis: the new yorker expõe face oculta e cruel dos estados unidos. Diálogos do Sul, 14 abr. 2020. Disponível em: https://dialogosdosul.operamundi.uol.com.br/permalink/64142. Acesso em: 10 maio 2020.

\section{Notas}

1 Artigo publicado no dia 14.02.20, na revista Science, e repercutido em sites de informações brasileiros.

2 Cenário Básico do Fundo, divulgado em abril/2020.

3 Ver Mineiro, Adhemar: A crise internacional do coronavírus: Uma conjuntura difícil no curto-prazo, e de mudanças importantes no médio e no longo prazo. Maio de 2020.

4 Ver Russo Júnior (2020).

5 O Vietnã é também, hoje, exemplo para o mundo de como enfrentar a pandemia. Com quase 96 milhões de habitantes e ocupando área pouco maior que a de Goiás, até 30.05.20 não tinha registrado uma única morte de covid-19 entre os 328 infectados, dos quais 279 já estavam curados. O isolamento social findou a 22 de abril, embora sejam mantidas medidas restritivas para bares, clubes, spas, teatros, centros esportivos etc. Estão proibidas reuniões com mais de 20 pessoas, e restaurantes e lanchonetes devem obedecer às diretrizes das autoridades locais. O país, que faz fronteira com a China, já havia adquirido experiência de como lidar com outras modalidades de coronavírus, como a SARS (2002) e a MERS (2012).

\section{José Álvaro de Lima Cardoso}

Doutor em Ciências Humanas pela Universidade Federal de Santa Catarina (UFSC)

Economista e Supervisor Técnico do Departamento Intersindical de Estatísticas e Estudos Sócio Econômicos, Escritório Regional de Santa Catarina (DIEESE)

\section{DIEESE}

Avenida Mauro Ramos, 1624 - Centro

Florianópolis - Santa Catarina - Brasil CEP 88020-302

\section{Agradecimentos \\ Não se aplica. \\ Agência financiadora \\ Não se aplica.}

Contribuições das autoras

Não se aplica.

\author{
Aprovação por Comitê de Ética e consentimento para parti- \\ cipação \\ Não se aplica. \\ Consentimento para publicação \\ Consentimento do autor. \\ Conflito de interesses \\ Não há conflito de interesses.
}

